\title{
2-Thienyl as Auxiliary Group in Mixed Lithium Diorganocuprates
}

\author{
Eva-Lotte Lindstedt and Martin Nilsson*
}

Department of Organic Chemistry, Chalmers University of Technology, S-41296 Göteborg, Sweden

\begin{abstract}
Lindstedt, Eva-Lotte and Nilsson, Martin, 1986. 2-Thienyl as Auxiliary Group in Mixed Lithium Diorganocuprates. - Acta Chem. Scand. B 40: 466-469.

2-Thienylcopper (ThCu) gives mixed lithium organothienylcuprate reagents (LiRThCu) with organolithium compounds $(\mathrm{R}=$ methyl, butyl, phenyl and 2-pyridyl) in ether. These cuprates react with enones or enoates adding the group $R$, 1,4 to the substrates, 2-thienylcopper being regenerated. The isolated yields of conjugate adducts are substantial (40-89\%) and comparable to those obtained with $\mathrm{LiR}_{2} \mathrm{Cu}$ in corresponding additions. Since the mixed organothienylcuprates are rather stable at $0^{\circ} \mathrm{C}$, and sometimes even at room temperature, the 2-thienyl group is an useful auxiliary in mixed lithium organocuprates for conjugate additions. Lithium bis(2-thienyl)cuprate, on the other hand, gives 1,2- as well as 1,4addition of the 2-thienyl group to enones and to methyl crotonate.
\end{abstract}

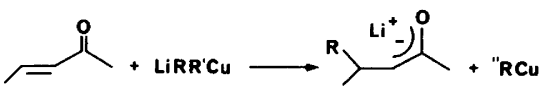

Mixed organocuprates, $\mathrm{LiRR}^{\prime} \mathrm{Cu}$, are useful reagents in conjugate additions and allow an economical use of precious organic groups. ${ }^{1}$ The phenylthiolate group has been much used with heterocuprates due to its ability to thermally stabilise cuprates. ${ }^{2}$ Cyanide and thiocyanate have recently been employed as auxiliary groups in reactive cuprates of higher order, $\mathrm{Li}_{2} \mathrm{R}_{2} \mathrm{CuCN}{ }^{3}$ Anions from sulfones, ${ }^{4}$ as well as phosphide groups ${ }^{5}$ have also been introduced as stabilising groups in mixed cuprates. We have previously investigated the utility of the chiral 2(1-dimethylaminoethyl)phenyl group $\left(\mathrm{R}^{*}\right)$ as auxiliary in mixed cuprates, ${ }^{6-10}$ and observed some enantioselectivity in the conjugate addition of the 2-pyridyl group to enones. ${ }^{10}$ Working with the diastereoselective addition of the group $\mathrm{R}^{*}$ to some enones, we observed that the mixed 2-thienylcuprate, $\mathrm{LiR}^{*} \mathrm{ThCu}$, often gave better results than $\mathrm{LiR}_{2}{ }_{2} \mathrm{Cu}$, that no conjugate addition of the thienyl group took place, and 2-thienylcopper precipitated during the reaction. ${ }^{11.12}$ We have now explored further the 2-thienyl group as an auxiliary in organocuprates.

${ }^{*}$ To whom correspondence should be addressed.

\section{Results}

2-Thienylcopper prepared via thienyllithium was reacted in ether at $0^{\circ} \mathrm{C}$ with different organolithium compounds ( $\mathrm{RLi}, \mathrm{R}=$ methyl, butyl, phenyl and 2-pyridyl) to give mixed lithium organo-2-thienylcuprate reagents. The somewhat coloured, homogeneous solutions could be kept at $0^{\circ} \mathrm{C}$ or even at room temperature for several $h$ without decomposition. We chose some representative substrates: 4-phenyl-3-buten-2-one (benzalacetone); 2-cyclohexenone; methyl crotonate; and methyl cinnamate. For conjugate addition, the substrate was added to an ether solution of the cuprate. 2-Thienylcopper precipitated immediately and the reaction was complete within $20 \mathrm{~min}$. The yields of isolated conjugate adduct were in the range of $40-83 \%$. The results are summarized in Table 1.

The ratio of LiRThCu to substrate was kept slightly above unity, which proved sufficient even for the enoates. Additions of lithium dibutylcuprate gave essentially the same yields as lithium (butyl)(thienyl)cuprate. Although variation of the amount of lithium (butyl)(thienyl)cuprate in addition to 4-phenyl-3-buten-2-one showed a 
Table 1. Isolated yields (\%) (after distillation) from conjugate additions of $\mathrm{LiRThCu}$ and $\mathrm{LiR}_{2} \mathrm{Cu}$ to enones and enoates in ether at $0^{\circ} \mathrm{C}$ (ratios reagent/substrate given within brackets)

\begin{tabular}{lllll}
\hline & $\begin{array}{l}\text { 2-Cyclo- } \\
\text { hexenone }\end{array}$ & $\begin{array}{l}\text { 4-Phenyl-3- } \\
\text { buten-2-one }\end{array}$ & $\begin{array}{l}\text { Methyl } \\
\text { crotonate }\end{array}$ & $\begin{array}{l}\text { Methyl } \\
\text { cinnamate }\end{array}$ \\
\hline $\mathrm{LiMeThCu}_{\mathrm{LiMe}} \mathrm{Cu}$ & 0 & $77(1.25)$ & - & $45(1.25)$ \\
$\mathrm{LiBuThCu}_{\mathrm{LiBu}} \mathrm{Cu}$ & - & $78(1.2)^{21}$ & - & $79(3.7)^{21}$ \\
$\mathrm{LiPhThCu}_{\mathrm{LiPh}} \mathrm{Cu}$ & $62^{\mathrm{a}}(1.7)$ & $65(1.25)$ & $54(2.0)$ & $59(1.25)$ \\
$\mathrm{LiPyThCu}_{\mathrm{LiPy}} \mathrm{Cu}$ & 43 & 62.5 & - & - \\
& $59^{\mathrm{a}}(2.0)$ & $35^{\mathrm{b}}(1.25)$ & $65^{\mathrm{a}}(2.0)$ & $10^{\mathrm{c}}(1.25)$ \\
\hline
\end{tabular}

a Yields after flash chromatography.

${ }^{\circ}$ Biphenyl formation (about $45 \%$ estimated from GC-MS).

${ }^{c}$ Crystals, m.p. $144-145^{\circ} \mathrm{C}$.

Table 2. Isolated yields (\%) from conjugate additions of $\mathrm{LiBuThCu}$ to 4-phenyl-3-buten-2-one in ether (values for $\mathrm{LiBu}_{2} \mathrm{Cu}$ in brackets)

\begin{tabular}{lll}
\hline $\begin{array}{l}\text { Ratio } \\
\text { Reagent/Substrate }\end{array}$ & \multicolumn{2}{c}{ Yields based on } \\
& Reagent \\
\hline & 60 & 60 \\
1.25 & $65(62.5)$ & $52(50)$ \\
1.5 & 73 & 49 \\
2.0 & 73 & 36 \\
5 & 77 & 15 \\
10 & 78 & 8 \\
\hline
\end{tabular}

moderate increase in yields when a large excess of cuprate was used (see Table 2), we nevertheless chose $1.25 \mathrm{~mol}$ of cuprate per mol of substrate as a standard ratio. So far, we have not been able to add lithium methyl(2-thienyl)cuprate to the highly reactive 2 -cyclohexenone. Similar results have been reported for lithium methyl(hetero)cuprates. ${ }^{13}$

In no case, was conjugate addition of the thienyl group to the substrate observed, but, according to GC-MS evidence, small amounts of by- products such as $2,2^{\prime}$-bithienyl did form, as well as cross-coupling products such as 2-butylthiophene, 2-phenylthiophene and 2(2-pyridyl)thiophene. For further comparison, we prepared lithium bis(2-thienyl)cuprate and screened its reactions. 2-Cyclohexenone gave some 3(2-thienyl)cyclohexanone but also the 1,2-adduct and its dehydration products. Phenylbutenone gave mostly 1,2- addition products and also a dimer, the latter apparently being formed by base-catalysed cyclodimerisation. ${ }^{14}$ Thus, lithium bis(2thienyl)cuprate differs from other cuprates, being less regioselective and possibly more basic, as discussed below.

\section{Discussion}

The experiments indicate that the mixed thienylcuprates, $\mathrm{LiRThCu}$, are more stable, less reactive, and more selective than $\mathrm{LiR}_{2} \mathrm{Cu}$. The yields for the conjugate additions are nevertheless comparable to those obtained with $\mathrm{LiR}_{2} \mathrm{Cu}$. Note, however, that in the formation of 2,2'-bithienyl, 2-butylthiophene etc., decomposition of the cuprate may sometimes be an important side re-

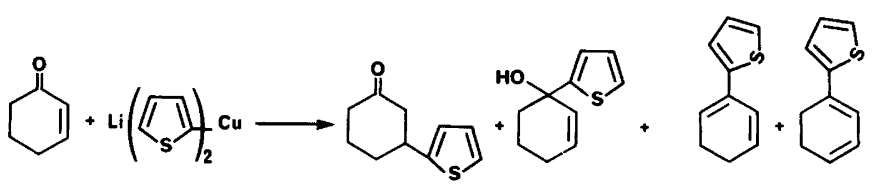


action. In mixed cuprates, $\mathrm{LiRR}^{\prime} \mathrm{Cu}$, in which the groups $R$ and $R^{\prime}$ are similar, it is not always easy to predict which of the groups will add to any particular substrate, and the product distribution may be affected even by the choice of solvent. ${ }^{14.15}$ When the $R$ groups are very different, the results of conjugate additions are often rationalised in thermodynamic terms: the "more stable" organocopper compound is reformed, and the other group is incorporated in the newly produced lithium enolate. From this standpoint, 2-thienylcopper is more stable than 2(1-dimethylaminoethyl)phenylcopper. The selectivity of lithium (2-pyridyl)(2-thienyl)cuprate can be compared with lithium (phenyl)(2-pyridyl)cuprate which also transfers only the pyridyl group to enones or enoates. ${ }^{16}$

Though we do not know the detailed structures of 2-thienylcopper or the (mixed) thienylcuprates, we can describe the copper-thienyl bond as being "strong", as it is apparently conserved during the reaction. In this context, the 1,2 - additions observed with lithium bis(2-thienyl)cuprate may seem surprising. Lipshutz et al. ${ }^{17}$ have observed 1,2-addition of the 2-thienyl group when $\mathrm{R}$ (2-thienyl) $\mathrm{Cu}(\mathrm{CN}) \mathrm{Li}_{2}$ was reacted with hindered (mostly $\beta, \beta$ disubstituted) substrates. One tentative explanation for our results is dissociation of lithium bis(2-thienyl)cuprate into thienylcopper and thienyllithium. The analogous 1,2addition with lithium bis(3-furyl)cuprate has been discussed in terms of the "hardness of the 3furyl group". ${ }^{18.19}$

In conclusion, the present work demonstrates the utility of the readily and cheaply available 2thienyl group as a "dummy" ligand in mixed cuprates.

\section{Experimental}

All reactions were performed under nitrogen or argon atmosphere with dry equipment. Diethyl ether was used as solvent for all reactions and was distilled from sodium benzophenone ketyl. Commercial (Fluka) butyllithium in hexane, methyllithium in ether, and phenyllithium in either hexane or benzene/ether were used. Copper iodide was purified via potassium diiodocuprate. 2-Pyridyllithium was prepared from 2-bromopyridine. ${ }^{16}$

Reaction mixtures were hydrolysed by addition of aqueous ammonia/ammonium chloride at $\mathrm{pH}$
8. For the pyridyl adducts, the ether layer was extracted with $2 \mathrm{M} \mathrm{HCl}$ and the aqueous phase was then made basic with either $2 \mathrm{M} \mathrm{NaOH}$ (when an enone was used as substrate) or aqueous ammonia in the enoate case. Products were distilled using a Büchi Kugelrohr apparatus and, when necessary, flash chromatographed on silica gel, eluting with $5-10 \%$ ethyl acetate in light petroleum (b.p. $40-60^{\circ} \mathrm{C}$ ). All products were characterised by gas chromatography (HP 5880, OV 17), gas chromatography/mass spectrometry (Finnigan 1020, capillary column) and ${ }^{1} \mathrm{H}-\mathrm{NMR}$ (Bruker WH 270).

Mixed lithium organo(2-thienyl)cuprates. Butyllithium $(5 \mathrm{mmol})$ was added to an ice-cooled solution of thiophene $(6 \mathrm{mmol})$ in ether $(10 \mathrm{ml})$ and the solution stirred at room temperature for at least $40 \mathrm{~min}$. Another $10 \mathrm{ml}$ of ether was added, the mixture cooled in ice, and finely powdered copper iodide added. 2-Thienylcopper formed immediately as a yellowish suspension. The mixture was stirred for about five min at room temperature, recooled in an ice bath, and the relevant organolithium compound $(4.85-4.95 \mathrm{mmol})$ then added. The mixture changed colour. It was then stirred until the Gilman test for free alkylor aryllithium ${ }^{20}$ was negative (about 5 to $15 \mathrm{~min}$ ). The substrate dissolved in ether ( 3 to $6 \mathrm{ml}$ ) was added to the cuprate mixture with a syringe. The reactions, followed by GLC, were complete within 10 to $20 \mathrm{~min}$.

Lithium bis(2-thienyl)cuprate. 2-Thienyllithium was prepared as above in two flasks. Ether $(3 \mathrm{ml})$ and copper iodide were added to one of them giving 2-thienylcopper. 2-Thienyllithium from the other flask $(4.8-4.9 \mathrm{mmol})$ was added until the yellow precipitate had dissolved to give a homogeneous pale yellow solution. Addition of the substrate resulted in most cases in a yellow mixture and a precipitate. Quenching and work-up procedures were as described for the mixed cuprates.

Acknowledgements. This work was supported by the National Swedish Board of Technical Development. We also thank Dr. Gerd Hallnemo for communicating preliminary results, Drs. Hans Malmberg and Christina Ullenius for valuable discussions and Dr. David Tanner for checking the language. 


\section{References}

1. Posner, G. H. Org. React. 19 (1972) 1.

2. Posner, G. H., Whitten, C. E. and Sterling, J. J. J. Am. Chem. Soc. 95 (1973) 7788.

3. Lipshutz, B. H. and Kozlowski, J. A. Tetrahedron 40 (1984) 5005.

4. Johnson, C. R. and Dhanoa, D. S. J. Chem. Soc. Chem. Comm. 1982, 358.

5. Bertz, S., Dabbagh, G. and Villacorta, G.J. J. Am. Chem. Soc. 104 (1982) 5824.

6. Malmberg, H., Nilsson, M. and Ullenius, C. Acta Chem. Scand. B 35 (1981) 625.

7. Hansson, A.-T., Rahman, M. T. and Ullenius, C. Acta Chem. Scand. B 32 (1978) 483.

8. Hansson, A.-T. and Nilsson, M. Tetrahedron 38 (1982) 389.

9. Gustavsson, B. Tetrahedron 34 (1978) 3023.

10. Malmberg, H. and Nilsson, M. J. Organomet. Chem. 243 (1983) 241.

11. Malmberg, H., Nilsson, M. and Ullenius, C. Tetrahedron Lett. 23 (1982) 3823.

12. Andersson, S., Jagner, S., Nilsson, M. and Urso, F. J. Organomet. Chem. 301 (1986) 257.
13. Gustavsson, B., Hallnemo, G. and Ullenius, C. Acta Chem. Scand. B34 (1980) 444.

14. Hallnemo, G. and Ullenius, C. Tetrahedron 39 (1983) 1621.

15. House, H. O. and Wilkins, J. M. J. Org. Chem. 43 (1978) 2443.

16. Malmberg, H. and Nilsson, M. Tetrahedron 38 (1982) 1509.

17. Lipshutz, B. H., Kozlowski, J. A., Parker, D. A., Nguyen, S. L. and McCarthy, K. E. J. Organomet. Chem. 285 (1985) 437.

18. Kojima, Y., Wakita, S. and Kato, N. Tetrahedron Lett. 47 (1979) 4577.

19. Ho, T. L. Tetrahedron 41 (1985) 1.

20. Houben/Weyl, Methoden der Organischen Chemie, Thieme Verlag, Stuttgart 1970. Vol. XIII, Chap. 1, p. 22.

21. House, H. O. and Umen, J. M. J. Org. Chem. 38 (1973) 3899.

Received December 18, 1985. 